\title{
Surfactant-modified flowerlike layered double hydroxide-coated magnetic nanoparticles for preconcentration of phthalate esters from environmental water samples
}

\author{
Xiaoli Zhao ${ }^{a}$, Shuangliu Liu ${ }^{a, b}$, Peifang Wang ${ }^{c}$, Zhi Tang $^{a}$, Hongyun Niu $^{\mathrm{b}}$, Yaqi Cai ${ }^{\mathrm{b}}$, \\ Fengchang $\mathrm{Wu}^{\mathrm{a}}$, Hao Wang ${ }^{\mathrm{a}}$, Wei Meng ${ }^{\mathrm{a}, *}$, John P. Giesy ${ }^{\mathrm{d}}$ \\ a State Key Laboratory of Environmental Criteria and Risk Assessment, Chinese Research Academy of Environmental Sciences, Beijing 100012, China \\ ${ }^{\mathrm{b}}$ State Key Laboratory of Environmental Chemistry and Ecotoxicology of Research Center for Eco-Environmental Sciences, Chinese Academy of Sciences, \\ Beijing 100085, China \\ ${ }^{\mathrm{c}}$ Key Laboratory of Integrated Regulation and Resource Development on Shallow Lakes, Ministry of Education, College of Environment, Hohai University, \\ Nanjing 210098, China \\ ${ }^{\mathrm{d}}$ Department of Veterinary Biomedical Sciences and Toxicology Centre, University of Saskatchewan, Saskatoon, Saskatchewan, Canada
}

\section{A R T I C L E I N F O}

\section{Article history:}

Received 17 March 2015

Received in revised form 24 July 2015

Accepted 31 July 2015

Available online 3 August 2015

\section{Keywords:}

Magnetic layered double hydroxide

Solid-phase extraction

Magnetic

Mixed hemimicelles

Surfactants

Concentration

\begin{abstract}
A B S T R A C T
A novel type of layered, flowerlike magnetic double hydroxide (MLDH) nanoparticles modified by surfactants has been successfully synthesized and was applied as an effective sorbent for pre-concentration of several phthalate ester pollutants (PAEs) from water prior to quantification. The MLDH was obtained via a simple ultrasound-assisted method by using silica coated $\mathrm{Fe}_{3} \mathrm{O}_{4}$ as the core and anisotropic $\mathrm{Mg}-\mathrm{Al}$ layered double hydroxide ( $\mathrm{Mg}-\mathrm{Al} \mathrm{LDH}$ ) nanocrystals as the shell to which analytes were absorbed. Orientation and dimensionality hierarchical structure as well as the large expandable interlayer free space and positive charge of the Mg-Al LDH shell make it easier to form anionic surfactant micelles on its surface via self-assembly. Due to its high adsorption area, compared with non-mesoporous nano solid-phase extraction agents, mesoporous channel shell and reduction diffusion path, MLDH exhibited high extraction efficiency of organic target residues. Under optimized conditions, with a total of $30 \mathrm{mg}$ of adsorbant added to from samples containing $400 \mathrm{~mL}$ water from the environment recoveries of DPP, DBP, DCP and DOP were consistent with ranges of $69-101 \%, 79-101 \%, 86-102 \%$ and $63-100 \%$, respectively. Standard deviations of recoveries ranged from 1 to $7 \%$, respectively and the method was sensitive with limits of detection of 12.3, 18.7, 36.5 and $15.6 \mathrm{ng} \mathrm{L}^{-1}$. To the best of our knowledge, this is the first report of use of surfactant-modified MLDH nanoparticles and its application as adsorbent to pre-concentration of PAEs from environmental water samples prior to instrumental analyses.
\end{abstract}

(c) 2015 Elsevier B.V. All rights reserved.

\section{Introduction}

Recently, due to their large adsorption area and high speed of equilibrium, nanomaterials have attracted attention for preconcentration [1-3]. However, there are several limitations, such as large backpressure and long sample loading time when they are packed into cartridges. To avoid these limitations, a novel (MSPE) method that uses magnetic nanoparticles as sorbents has been developed [4-8]. Most commonly used non-porous magnetic extractants tend to aggregate and agglomerate and be contaminated in complex

\footnotetext{
* Corresponding author.

E-mail address: mengwei@craes.org.cn (W. Meng).
}

matrices, which results in relatively poor adsorption capacities. Therefore, it was necessary to develop a novel MSPE agent which has a larger surface area and enrichment capability as well as better dispersity.

Layered, magnetic double hydroxide (MLDH) nanoparticles with large surface area, provide a low cost, three-dimensional structure that has demonstrated potential for use in drug delivery, catalysis, sensing, molecules and biology [9-15]. Orientation and dimensionality hierarchical structure as well as the large expandable interlayer free space make it easier to be further modified. Making MLDH magnetic facilitated an otherwise difficult solid-liquid separation, while the shell-type mesoporous structure shortens the diffusion path and increases the effective area, thus improving the adsorption capacity and extraction efficiency. Therefore, MLDH 
nanomaterials would be an idea candidate sorbents for MSPE. $\mathrm{Fe}_{3} \mathrm{O}_{4}-\mathrm{LDH}$ has been used as a dissolvable sorbent for extraction of PPCPs and phenolic acids, respectively $[16,17]$. After adsorption and extraction from water, analytes were eluted from the MLDH by dissolving the double hydroxide layers containing the analytes by changing the $\mathrm{pH}$ of the solution. To date, however, there have been few reports on application of MLDH in MSPE by use of hemimicelles/admicelles.

There are primarily two methods for producing MLDH. One is in situ growth, in which a continuous and uniform $\mathrm{AlOOH}$ coating is deposited on surfaces of $\mathrm{Fe}_{3} \mathrm{O}_{4} @ \mathrm{SiO}_{2}$ microspheres by use of a layer-by-layer method of assembly, which is then reacted with a divalent nitrate to produce the magnetic $M(I I) A l-L D H(M=N i$, $\mathrm{Co}, \mathrm{Zn}, \mathrm{Mg}$ ). Previous studies have established possible applications $[18,19]$. Previously flowerlike $\mathrm{Fe}_{3} \mathrm{O}_{4} @ \mathrm{SiO}_{2} @ \mathrm{NiAl}-\mathrm{LDH}$ were synthesized via in situ growth then applied for separation of a histidine(His)-tagged green fluorescent protein [18]. The other method, coprecipitation, uses synthesis of magnetic M(II)Al-LDH in a single step, without first forming the surface layer of AlOOH [10,12]. However, because the reaction in separate synthesis solutions for at least 10 repetitions each lasting $2 \mathrm{~h}$, the in situ grow of the $\mathrm{AlOOH}$ layer was time consuming. In addition, the LDH nanosheet needs to be heated in an autoclave at $100^{\circ} \mathrm{C}$ for $48 \mathrm{~h}$. The coprecipitation method also requires reaction for about $24 \mathrm{~h}$ under continuous heating. Therefore, it was deemed useful to develop a time-saving and simple method to obtain MLDH.

To further increase capacity for extraction and dispersity of nano-materials, their surfaces can be modified with special functional groups. Several groups, including ours, have synthesized various magnetic nanoparticles with various properties and applied them to the separation of target contaminants [3,20,21]. Among the many modified methods, one of the more mature techniques is to use a surfactant to form hemimicelles/admicelles on surfaces of magnetic nanoparticles via self-assembly behavior and then use hydrophobic interactions and electrostatic interactions between micelles and organic pollutants to achieve solid-phase extraction of the target compounds [22-26]. By combining the advantages of hemimicelles/admicelles and MLDH nanoparticles, a new hybrid type of admicelle MSPE sorbents with greater surface areas, chemical stability and good magnetic separability can be obtained.

In this study, a simple method to fabricate well dispersed flowerlike $\mathrm{Fe}_{3} \mathrm{O}_{4} @ \mathrm{SiO}_{2} @ \mathrm{Mg}-\mathrm{Al} \mathrm{MLDH}$ via ultrasound assisted direct growth of MgAl-LDH nanosheets on the surface of silica spheres is presented. The new MSPE sorbent was obtained by modification of MLDH with surfactant. The outstanding features of this MSPE method are: (1) The synthetic procedure of MLDH is efficient and saves time, uses lesser amounts of reagents, and has an excellent efficiency of production of MLDH without the need to heat the solution during formation; (2) The flowerlike and mesoporous shell structure of the MLDH increases the effective area, reduces lengths of pathways of diffusion, and thus improves extraction capacity and efficiency; (3) Self-assembly of the MLDH coated with surfactant improves capacity for extraction without requiring any special conditions such as high temperature or pressure; (4) Due to the rapidity of separation of the MLDH particles from water, the entire extraction process can be completed within $15 \mathrm{~min}$. To examine the feasibility of this approach, several phthalate ester pollutants (PAEs) were selected as model compounds. Coupling this novel SPE technique with high-performance liquid chromatography for separation and fluorescence for detection, a highly selective SPE HPLC with a PDA-100 ultraviolet detector analytical method was established. The reliability of this method was demonstrated by extraction and analysis of the four target compounds in environmental water samples.

\section{Experimental}

\subsection{Materials and instrumentation}

Dipropyl phthalate (DPP), dibutyl phthalate (DBP), dicyclohexyl phthalate (DCP), dioctyl-phthalate (DOP) and tetraethoxysilane (TEOS) were purchased from AccuStandard (New Haven, USA). Standard stock solutions $\left(500 \mathrm{~g} \mathrm{~mL}^{-1}\right)$ containing these compounds were prepared in methanol and stored at $4{ }^{\circ} \mathrm{C}$. Working solutions were prepared daily by appropriate dilution of the stock solutions with water. Sodium hydroxide and hydrochloric acid were guarantee grade reagents (Beijing Chemicals Corporation, Beijing, China). HPLC-grade methanol and acetonitrile were purchased from Merck (Darmstadt, Germany). Ammonium hydroxide (28\%, w/w), $\mathrm{FeCl}_{3} \cdot 6 \mathrm{H}_{2} \mathrm{O}, \mathrm{Al}\left(\mathrm{NO}_{3}\right)_{3} \cdot 9 \mathrm{H}_{2} \mathrm{O}, \mathrm{Mg}\left(\mathrm{NO}_{3}\right)_{2} \cdot 6 \mathrm{H}_{2} \mathrm{O}, \mathrm{NaCl}$, absolute ethyl alcohol, sodium dodecyl sulfate (SDS), sodium hydroxide, sodium bicarbonate and hydrochloric acid were purchased from Beijing Chemical Regent Company, without further purification before use. Ultrapure water used in all of the experiments was prepared by using Milli-QSP reagent water system (Millipore, Bedford, MA, USA).

\subsection{Preparation of $\mathrm{Fe}_{3} \mathrm{O}_{4} @ \mathrm{SiO}_{2} @ M g-A l L D H$ particles}

Herein, we present a simple method to fabricate well dispersed $\mathrm{Fe}_{3} \mathrm{O}_{4} @ \mathrm{SiO}_{2} @ \mathrm{Mg}-\mathrm{Al} \mathrm{LDH}$ via ultrasound assisted direct growth of $\mathrm{Mg}-\mathrm{Al} \mathrm{LDH}$ nanosheets on the surface of silica spheres (Fig. 1). Uniform-sized, magnetite nanoparticles of approximately $200 \mathrm{~nm}$ were synthesized and used as the magnetic core that allows rapid separation by use of a magnet [27]. Briefly, $2.7 \mathrm{~g} \mathrm{FeCl}_{3} \cdot 6 \mathrm{H}_{2} \mathrm{O}, 1.0 \mathrm{~g}$ sodium citrate and $4.8 \mathrm{~g} \mathrm{NaAc}$ were dissolved in $80 \mathrm{~mL}$ ethylene glycol. A uniform, yellow liquid formed after magnetically stirring for half an hour. The above mixed liquor was then transferred to a Teflon-lined stainless-steel autoclave and heated at $200^{\circ} \mathrm{C}$ for $10 \mathrm{~h}$. The resultant $\mathrm{Fe}_{3} \mathrm{O}_{4}$ microspheres were collected, washed with ethanol several times, and dried at $50^{\circ} \mathrm{C}$ under vacuum.

In order to improve stability of the magnetic core and generate regular LDH shell, $\mathrm{Fe}_{3} \mathrm{O}_{4} @ \mathrm{SiO}_{2}$ microspheres were obtained through a versatile sol-gel method. In brief, magnetite $\mathrm{Fe}_{3} \mathrm{O}_{4}$ $(0.85 \mathrm{~g})$ was dispersed in a round-bottom flask charged with ethanol $(200 \mathrm{~mL})$, water $(50 \mathrm{~mL})$ and concentrated ammonia solution (3.60 mL, $28 \mathrm{wt} . \%)$. The suspension was ultrasonicated for $30 \mathrm{~min}$ (ultrasonic cleaner, KQ-500DE, $500 \mathrm{~W}, 40 \mathrm{kHz}$ ). Then, $2.5 \mathrm{~mL}$ of tetraethyl orthosilicate (TEOS) was added drop-wise followed by continuous mechanical stirring for $8 \mathrm{~h}$. The resultant $\mathrm{Fe}_{3} \mathrm{O}_{4} @ \mathrm{SiO}_{2}$ microspheres were collected from the reaction mixture under an external magnetic field, washed with ethanol several times, and dried at $50^{\circ} \mathrm{C}$ under vacuum.

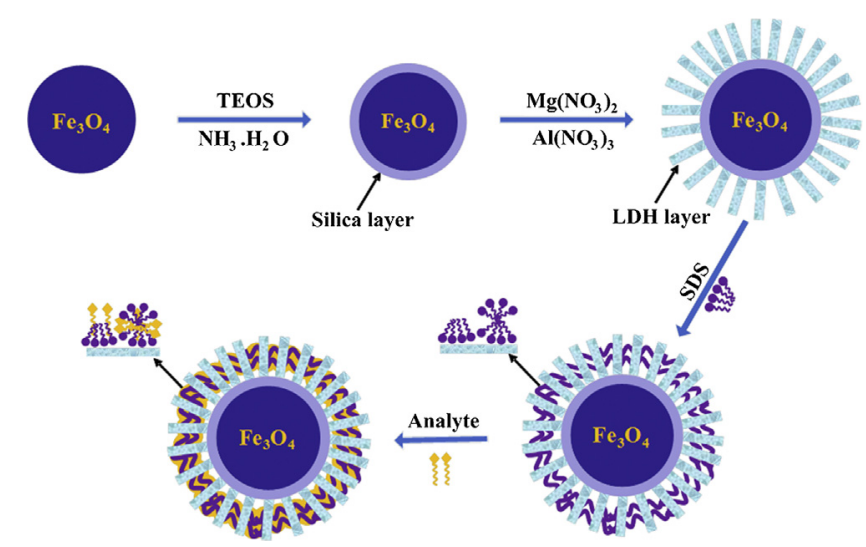

Fig. 1. Schematic illustration of the preparation of surfactants modified $\mathrm{Fe}_{3} \mathrm{O}_{4} @ \mathrm{SiO}_{2} @ \mathrm{Mg}-\mathrm{Al} \mathrm{MLDH}$ and its application for enrich analytes as SPE sorbents. 
Nanoflakes of Mg-Al LDH were perpendicularly deposited onto $\mathrm{Fe}_{3} \mathrm{O}_{4} @ \mathrm{SiO}_{2}$ microspheres by use of a sonication method to form $\mathrm{Fe}_{3} \mathrm{O}_{4} @ \mathrm{SiO}_{2} @ \mathrm{Mg}-\mathrm{Al} \mathrm{LDH}$ (denoted as MLDH).Compared with other methods, the MLDH systems described here that apply ultrasound can be completed within $2 \mathrm{~h}$ at room temperature. Also, the procedure for making MLDH uses lesser amounts of reagents, and provided high throughput without heating. A mass of $0.1 \mathrm{~g}$ $\mathrm{Fe}_{3} \mathrm{O}_{4} @ \mathrm{SiO}_{2}$ microsphere particles were dispersed in $50 \mathrm{~mL}$ deionized water, with the $\mathrm{pH}$ adjusted to 10 (the $\mathrm{pH}$ buffered solution for adjusting was obtained by dissolving $1.28 \mathrm{~g} \mathrm{Na}_{2} \mathrm{CO}_{3}$ and $1.6 \mathrm{~g}$ $\mathrm{NaOH}$ in $100 \mathrm{~mL}$ of a $1: 1(v: v)$ methanol-water solution. Then $20 \mathrm{~mL}$ aqueous solution containing $1.44 \mathrm{mmol} \mathrm{Mg}\left(\mathrm{NO}_{3}\right)_{2} \cdot 6 \mathrm{H}_{2} \mathrm{O}$ and $0.48 \mathrm{mmol} \mathrm{Al}\left(\mathrm{NO}_{3}\right)_{3} \cdot 9 \mathrm{H}_{2} \mathrm{O}$ was added drop-wise to the suspension of $\mathrm{Fe}_{3} \mathrm{O}_{4} @ \mathrm{SiO}_{2}$ at a rate of $1 \mathrm{~mL} \mathrm{~min}^{-1}$ controlled by peristaltic pump under vigorous stirring and the solution $\mathrm{pH}$ maintained at $\mathrm{pH} 10$. The above reaction was under ultrasonication for $1 \mathrm{~h}$, and then products were collected and redispersed in $70 \mathrm{~mL}$ of deionized water for further ultrasound dispersion for $1 \mathrm{~h}$. Particles of $\mathrm{Fe}_{3} \mathrm{O}_{4} @ \mathrm{SiO}_{2} @ \mathrm{Mg}-\mathrm{Al} \mathrm{LDH}$ were collected from the reaction mixture under an external magnetic field, and dried at $50^{\circ} \mathrm{C}$ under vacuum.

\subsection{Characterization of adsorbents}

Transmission electron microscopy (TEM; H-7500, Hitachi, Tokyo, Japan) was used to observe morphology and sizes of particles of various magnetic nanoparticles. Magnetic properties of materials were acquired by a vibrating sample magnetometer (VSM, LDJ9600, Troy, MI) at room temperature with the magnetic field intensity varied from $+20,000$ to $-20,000$ Oe. Fourier transform IR (FTIR) spectra of MLDH and intermediate products were measured by using a Nicolet AVATAR 360 FTIR spectrometer (IR, Nicolet Avatar 360, Waltham, MA). The phase analysis was conducted for each material by using a PANalyticalX'pert Pro X-ray diffraction crystal analyzer (XRD, PANalytical, Almelo, Netherlands) with nickel-filtered $\mathrm{CuK} \alpha$ radiation with a scan rate of $4.0^{\circ} \mathrm{min}^{-1}$ and scanning range from $10^{\circ}$ to $80^{\circ}$. The nitrogen adsorption - Brunauer-Emmett-Teller (BET) adsorption method (ASAP2000V3.01A; Micromeritics, Norcross, GA) was adopted for measuring specific surface areas of materials, and the Barrett-Joyner-Halenda (BJH) method were adopted for measuring pore volume and distribution of pore size of the materials. X-ray photoelectron spectroscopy (XPS) was conducted by applying an ESCA-Lab-200i-XL spectrometer (Thermo Scientific, Waltham, MA) with monochromatic $\mathrm{Al} \mathrm{K} \alpha$ radiation $(1486.6 \mathrm{eV})$.

\subsection{Solid-phase extraction process}

A magnetic field was used to separate solids from suspension during solid-phase extraction. This was similar to that of magnetic nano extracting agent that has been reported previously by our group [22,28]. In brief, 30 mg of $\mathrm{Fe}_{3} \mathrm{O}_{4} @ \mathrm{SiO}_{2} @ \mathrm{MgAl}-\mathrm{LDH}$ and $20 \mathrm{mg}$ of SDS were added to $400 \mathrm{~mL}$ of phthalate esters (PAEs) water sample under ultrasonication for $30 \mathrm{~s}$ and $\mathrm{pH}$ was adjusted to 4.5 with $0.1 \mathrm{M} \mathrm{NaOH}$ or $\mathrm{HCl}$. The mixture was then placed into a beaker and allowed to equilibrate for $20 \mathrm{~min}$ to completely trap target analytes. After reaching equilibrium, a Nd-Fe-B rectangle strong magnet $(150 \mathrm{~mm} \times 130 \mathrm{~mm} \times 50 \mathrm{~mm})$ was deposited at the bottom of the beaker to isolate $\mathrm{Fe}_{3} \mathrm{O}_{4} @ \mathrm{SiO}_{2} @ \mathrm{Mg}-\mathrm{Al} \mathrm{LDH}$ that adsorbed target compound from the suspension. After about $5 \mathrm{~min}$, the suspension became clarified and the supernatant was decanted. Finally, preconcentrated PAEs analytes were eluted from the MLDH sorbent with $12 \mathrm{~mL}$ ( $4 \mathrm{~mL}$ for each time) of acetonitrile. The eluate was concentrated to $0.5 \mathrm{~mL}$ with a stream of nitrogen, and $20 \mu \mathrm{L}$ of this solution was injected into HPLC system for analysis.

\subsection{Analysis of HPLC}

Identification and quantification of analytes was performed by use of a liquid chromatography system (Dionex, Sunnyvale, CA USA). The HPLC equipment included a DIONEX P680 pump, a TCC100 thermostated column compartment, an ASI-100 automatic sampler and a PDA-100 ultraviolet detector. Chromatographic separation was conducted by use of in the Diamonsil C18 column $(250 \mathrm{~mm} \times 4.6 \mathrm{~mm}$; particle size, $5 \mu \mathrm{m})$ (Dikma Technologies, Beijing, China). The detector was set to a wavelength of $226 \mathrm{~nm}$. Separation was achieved by use of gradient elution where $50 \%$ aqueous acetonitrile and pure acetonitrile were used respectively as mobile phase $B$ and $A$, with $1 \mathrm{~mL} \mathrm{~min}^{-1}$ for velocity of flow. The procedures of gradient elution were as follows: Mobile phase B was remained at $40 \%$ in the first $15 \mathrm{~min}$; then it increased to $100 \%$ within $10 \mathrm{~min}$, and kept at that value for $10 \mathrm{~min}$ before the mobile phase $B$ was returned to its initial state within $3 \mathrm{~min}$.

\subsection{Sample collection and quality control}

Samples of surface waters were collected from different districts of Beijing, China in October 2014. River water was collected from $10 \mathrm{~cm}$ under the surface of the Beiyun and Juma Rivers in Beijing. Samples of tap-water were taken from laboratory of Research Center for Eco-environment Science, Chinese Academy of Science, Haidian District, Beijing. Water was filtered with $0.22 \mu \mathrm{m}$ of nylon filter membrane and then stored in the refrigerator at $4{ }^{\circ} \mathrm{C}$. Measurements were completed within one week. In order to eliminate possible contamination of containers or equipment in the processes of sampling and conducting experiments, all containers and equipment should be rinsed with methyl alcohol for more than 3 times, and then dried at $150^{\circ} \mathrm{C}$ under vacuum. Blanks were performed with ultrapure water following similar procedures, and none of the target PAEs was detected in the result.

\section{Results and discussion}

\subsection{Particle size and morphology of materials}

TEM and SEM images depict the size and structure of nanoparticles. Prepared magnetic $\mathrm{Fe}_{3} \mathrm{O}_{4}$ possessed a homogeneous spherical structure with a mean diameter of $200 \mathrm{~nm}$ and disperse well in aqueous solution (Fig. 2A). After being coated with a smooth silica layer, typically core-shell $\mathrm{Fe}_{3} \mathrm{O}_{4} @ \mathrm{SiO}_{2}$ microspheres with a thin silica layer of $25 \mathrm{~nm}$ in thickness were obtained (Fig. 2B). $\mathrm{Fe}_{3} \mathrm{O}_{4} @ \mathrm{SiO}_{2} @ \mathrm{Mg}-\mathrm{Al} \mathrm{LDH}$ particles were composed of a compact core and a lower density shell (Fig. 2C). The $\mathrm{Fe}_{3} \mathrm{O}_{4} @ \mathrm{SiO}_{2} @ \mathrm{Mg}-\mathrm{Al}$ LDH microspheres had a uniform lamellar, flowerlike structure with numerous nanoflakes perpendicularly grafted to the surface of $\mathrm{SiO}_{2}$, which leaves open space among them, with a gap between nanosheets sufficient to provide positions for subsequent modifications. These are the correct conditions to allow further reactions with analytes.

\subsection{Analysis of crystalline phase for materials}

Crystal phases of materials were investigated by use of XRD analysis. All the curves showed that the crystalline structure of the magnetic core at different stages of formation was face-centered cubic $\mathrm{Fe}_{3} \mathrm{O}_{4}$ (JCPDS card 19-629) (Fig. 3A) [29]. After being coated by the layer of silica, the characteristic diffraction peaks of amorphous $\mathrm{SiO}_{2}$ were increased, which indicated that the surface of $\mathrm{Fe}_{3} \mathrm{O}_{4} \mathrm{NPs}$ had formed the dense outer layer of $\mathrm{SiO}_{2}$. On the curve of $\mathrm{Fe}_{3} \mathrm{O}_{4} @ \mathrm{SiO}_{2} @ \mathrm{Mg}-\mathrm{Al} \mathrm{LDH}$, the greater peaks at $2 \theta=10.25^{\circ}, 23.01^{\circ}$, $38.43^{\circ}$ and $61.77^{\circ}$ can be ascribed to typical and highly crystallized $\mathrm{Mg}-\mathrm{Al} \mathrm{LDH}$ shell [9]. 


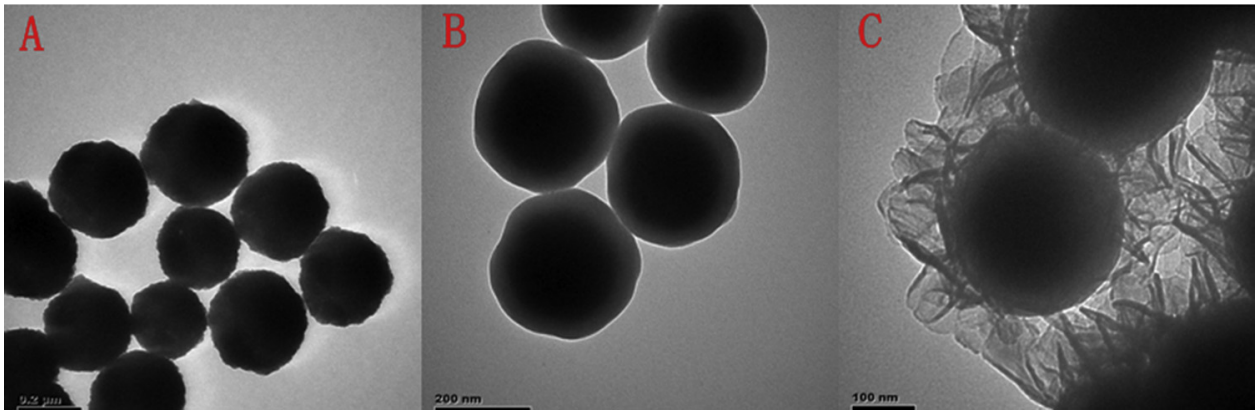

Fig. 2. TEM and $\mathrm{SEM}$ images of $(\mathrm{A}) \mathrm{Fe}_{3} \mathrm{O}_{4}$, (B) $\mathrm{Fe}_{3} \mathrm{O}_{4} @ \mathrm{SiO}_{2}$ and (C) $\mathrm{Fe}_{3} \mathrm{O}_{4} @ \mathrm{SiO}_{2} @ \mathrm{Mg}-\mathrm{Al} \mathrm{LDH}$.
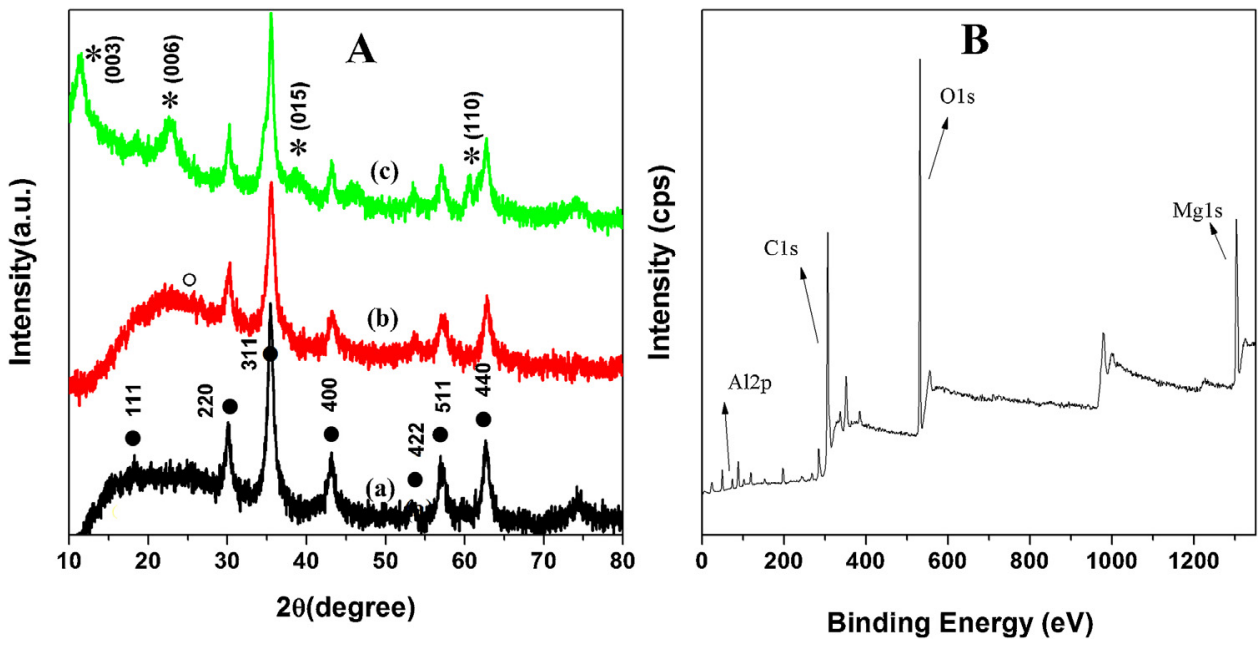

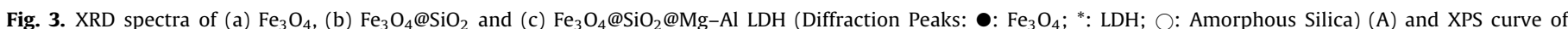
$\mathrm{Fe}_{3} \mathrm{O}_{4} @ \mathrm{SiO}_{2} @ \mathrm{Mg}-\mathrm{Al} \mathrm{LDH}(\mathrm{B})$.

\subsection{XPS spectrum of $\mathrm{Fe}_{3} \mathrm{O}_{4} @ \mathrm{SiO}_{2} @ M g-A l L D H$}

Concentrations of metals on surfaces of the particles were obtained from the XPS analysis. The XPS curve for $\mathrm{Fe}_{3} \mathrm{O}_{4} @ \mathrm{SiO}_{2} @ \mathrm{Mg}-\mathrm{Al} \mathrm{LDH}$ had characteristic peaks of $\mathrm{Mg} 1 \mathrm{~s}$ and Al2p (Fig. 3B), which further indicated that the prepared nanomaterials had the typical core-shell structure; surface of the materials was the double metal layer structure of $\mathrm{Mg}-\mathrm{Al}$, proving the successful synthesis of magnetic $\mathrm{Mg}-\mathrm{Al} \mathrm{LDH}$, which was consistent with the analysis of the surfaces by use of TEM, SEM, XRD and FTIR.

\subsection{Infrared spectra of all the materials}

Functional groups on surfaces were investigated by use of infrared spectra. In the infrared spectra of $\mathrm{Fe}_{3} \mathrm{O}_{4}$, the absorption peak at $1400 \mathrm{~cm}^{-1}$ was due to $\mathrm{COO}-$ which was modified on the surface of $\mathrm{Fe}_{3} \mathrm{O}_{4}$, and the peak at $1626 \mathrm{~cm}^{-1}$ was due to overlapping vibrations of $\mathrm{COO}-$ and $\mathrm{O}-\mathrm{H}$ groups [30,31]. The peaks observed at 585 and $3434 \mathrm{~cm}^{-1}$ were due to stretching vibrations of $\mathrm{Fe}-\mathrm{O}$ and $\mathrm{O}-\mathrm{H}$ groups [32]. The peak at $585 \mathrm{~cm}^{-1}$ was observed for all three materials; however, the strengths became less as they were coated by layers of $\mathrm{SiO}_{2}$ and $\mathrm{LDH}$, which was mainly caused by core-shell structures of the prepared $\mathrm{Fe}_{3} \mathrm{O}_{4} @ \mathrm{SiO}_{2} \mathrm{NPs}$ and $\mathrm{Fe}_{3} \mathrm{O}_{4} @ \mathrm{SiO}_{2} @ \mathrm{Mg}-\mathrm{Al}$ LDH. Compared with the standard infrared spectrum of $\mathrm{Fe}_{3} \mathrm{O}_{4}$, magnetic silica particles of $\mathrm{Fe}_{3} \mathrm{O}_{4} @ \mathrm{SiO}_{2}$ and magnetic particles with double metal hydroxides of $\mathrm{Fe}_{3} \mathrm{O}_{4} @ \mathrm{SiO}_{2} @ \mathrm{Mg}-\mathrm{Al} \mathrm{LDH}$ synthesized during this project, had more characteristic peaks of $\mathrm{Si}-\mathrm{O}$ keys at $1080 \mathrm{~cm}^{-1}$, but the absorption peaks of COO- disappeared at the same time, which indicated that the iron core of $\mathrm{Fe}_{3} \mathrm{O}_{4}$ was completely covered [8]. With introduction of the LDH layer, strengths of peaks at 3434 and $1626 \mathrm{~cm}^{-1}$ increased. Simultaneously, a new absorption peak was caused by the $\mathrm{NO}_{3}{ }^{-}$group. It was also shown that $\mathrm{Fe}_{3} \mathrm{O}_{4} @ \mathrm{SiO}_{2} @ \mathrm{Mg}-\mathrm{Al}$ LDH materials exhibited a typical Mg-Al LDH feature that was the ideal core-shell structure and surface for adsorption of organic molecules.

\subsection{Magnetic properties of materials}

Magnetic properties of the as-synthesized microspheres prepared for MSPE at different stages all exhibited typical superparamagnetism, and the remanence and coercive force on the magnetization curve were almost zero. With increase of non-magnetic components, saturation magnetization of $\mathrm{Fe}_{3} \mathrm{O}_{4} @ \mathrm{SiO}_{2}$ and $\mathrm{Fe}_{3} \mathrm{O}_{4} @ \mathrm{SiO}_{2} @ \mathrm{Mg}-\mathrm{Al}$ LDH decreased slightly compared with that of $\mathrm{Fe}_{3} \mathrm{O}_{4}$. Maximal magnetization of prepared $\mathrm{Fe}_{3} \mathrm{O}_{4} @ \mathrm{SiO}_{2} @ \mathrm{Mg}-\mathrm{Al} \mathrm{LDH}$ was $29.62 \mathrm{emu} \mathrm{g}^{-1}$, which fully met the requirements for magnetic separation during SPE for organic molecules. Superparamagnetism of the extracting agent MLDH, which fully dispersed in the water in the absence of an external magnetic field, allowed it to be rapidly scavenged in the presence of a magnetic field.

\subsection{Specific surface area and distribution of pore size of $\mathrm{Fe}_{3} \mathrm{O}_{4} @ \mathrm{SiO}_{2} @ \mathrm{Mg}-\mathrm{Al} L \mathrm{LH}$}

The specific surface area and pore size of magnetic sorbents can affect efficiency of extraction. Curves for adsorption and desorption of $\mathrm{N}_{2}$ by particles of $\mathrm{Fe}_{3} \mathrm{O}_{4} @ \mathrm{SiO}_{2} @ \mathrm{Mg}-\mathrm{Al}$ LDH exhibits IV-type 


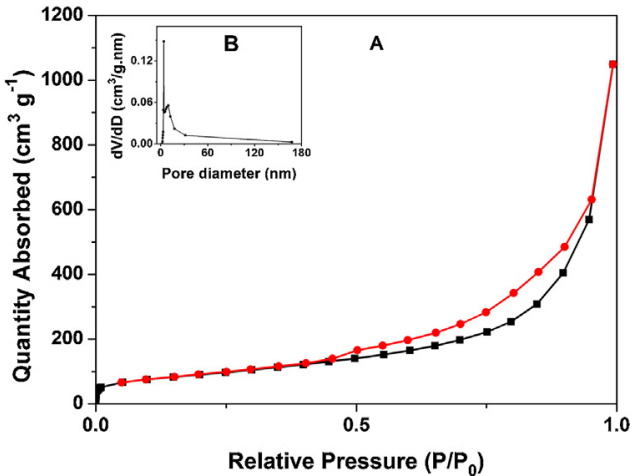

Fig. 4. Nitrogen adsorption curve (A) and pore size distribution curve (B) of $\mathrm{Fe}_{3} \mathrm{O}_{4} @ \mathrm{SiO}_{2} @ \mathrm{Mg}-\mathrm{Al} \mathrm{LDH}$.

with a H3-type hysteresis loops, indicating that the pore size is close to being mesoporous (Fig. 4C). The curve of pore size distribution had a sharp peak (Fig. 4B), which indicated that the pore structure of mesoporous materials was rather clear and neat, and that most sizes of mesoporous were uniform with fewer micropores. The special surface area, pore volume and pore diameter of MLDH were calculated to be $354.82 \mathrm{~m}^{2} \mathrm{~g}^{-1}, 1.63 \mathrm{~cm}^{3} \mathrm{~g}^{-1}$, and $2.73 \mathrm{~nm}$, respectively.

\subsection{Effect of $p H$ on extraction of PAEs}

Hydrogen ion activity of the solution, represented by $\mathrm{pH}$, might affect the type and density of charges on the surface of nanomaterials, as well as the state of aggregation of surface active agent. Therefore, adsorption of target PAEs might have an effect on the extracting agent. Anionic, surface-active agent was absorbed onto the oxide surface through electrostatic attraction, and the charge density on the oxide surface had a significant effect on the process of self-assembly on the ionic surface-active agent. The charge density on the oxide surface changed as a function of $\mathrm{pH}$. When the $\mathrm{pH}$ was less than the isoelectric point of the oxide, the oxide surface carried a net positive charge; if the $\mathrm{pH}$ was greater than the isoelectric point, the oxide surface carried a net negative charge. The isoelectric point of $\mathrm{Fe}_{3} \mathrm{O}_{4} @ \mathrm{SiO}_{2} @ \mathrm{Mg}-\mathrm{Al} \mathrm{LDH}$ was approximately 11 [33]. Thus, under neutral or acidic conditions, surfaces of the extracting agent carried a stronger positive charge, such that the hydrophilic ends with negative charge on the sodium dodecyl sulfate (SDS) of the anionic surface active agent were strongly adsorbed onto the surface of the metal oxide particles by electrostatic attraction, which could then form mixed micelles through absorption and selfassembly. When the $\mathrm{pH}$ was greater than 4, efficiency of extraction of PAEs was inversely proportional to $\mathrm{pH}$ (Fig. 5A). This was because the surface of $\mathrm{Mg}-\mathrm{Al} \mathrm{LDH}$ carried a net positive charge, and the isoelectric point was approximately 11 , such that with the greater $\mathrm{pH}$, it was nearer the isoelectric point, such that the density of surface charge gradually decreased [33]. Effective absorption of SDS micelles decreased, so that efficiency of extraction was reduced. When $\mathrm{pH}$ was 3, efficiency of extraction was reduced as well. This was because when $\mathrm{pH}$ was less than 4 , $\mathrm{LDH}$ would slowly dissolve, thereby affecting the effective surface area of MLDH, which also led to lesser adsorption of surfactant micelles, as well as efficiency of extraction [34]. Thus, to offset these contradictory forces and optimize conditions for adsorption a pH of 4.5 was chosen in subsequent experiments which were designed to investigate the effects of other conditions on efficiency of extraction.

\subsection{Effect of amount of MLDH on efficiency of extraction}

Large specific surface area and extraction capacity were both advantages of the use of a solid-phase nanomaterial as an extraction agent. Effects of amount $\mathrm{Fe}_{3} \mathrm{O}_{4} @ \mathrm{SiO}_{2} @ \mathrm{Mg}-\mathrm{Al} \mathrm{LDH}$ on efficiency of extraction was investigated by use of static equilibrium experiments similar to those described above. In this experiment, MLDH and SDS were added at a defined proportion (3:2), and then recoveries of various target chemicals were measured (Fig. 5B).
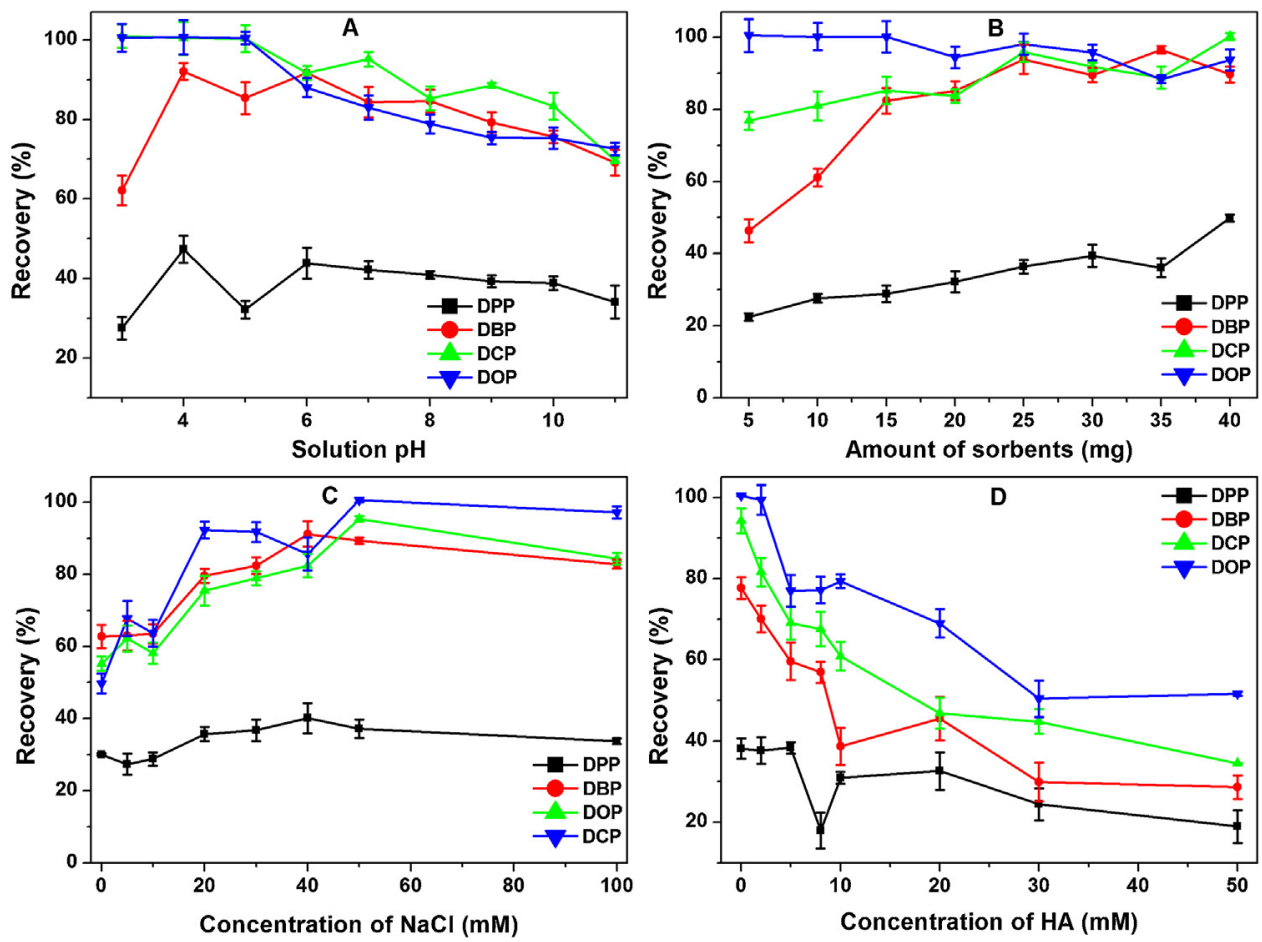

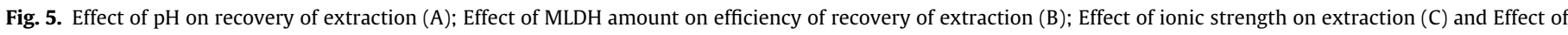
humic acid on efficiency of extraction (D). 
In general, efficiency of extraction was proportional to amount of MLDH used. Efficiency of extraction of PAEs gradually increased with the amount of MLDH added to a maximum at $25 \mathrm{mg}$ MLDH. For this reason $25 \mathrm{mg}$ of MLDH was chosen as the optimal amount for use in subsequent experiments. The optimal amounts of semimicelle/extracting agent used as the solid phase was less than that reported by other researchers $[22,23,28,35,36]$. In fact, the optimal amount of extracting agent determined in this study was $1 / 20$ of that of the amount of $\mathrm{Al}_{2} \mathrm{O}_{3}$ and $\mathrm{SiO}_{2}$ particles modified by surfactant that was observed in previous studies [28]. Also, when the results of this study were compared with those of previous studies using nano-particles of $\mathrm{Fe}_{3} \mathrm{O}_{4}$, the amount of $\mathrm{Fe}_{3} \mathrm{O}_{4} @ \mathrm{SiO}_{2} @ \mathrm{Mg}-\mathrm{Al}$ LDH was only a quarter of the amount required previously, which demonstrated the greater efficiency of MLDH as the solid-phase extraction agent [23].

\subsection{Effect of SDS amount on extraction recovery}

Efficiency of recovery of spiked materials was initially directly proportional to the amount of surfactant, up to a maximum, thereafter the efficiency of extraction was inversely proportional to the amount of surfactant added. This was because when surfactant was not added, the efficiency of extraction PAEs by MLDH was inversely proportional to the amount of, semi-micelles, mixedmicelles and micelles formed on the surface of the MLDH. Although when an excessive amount of SDS was added, the extra SDS would be dispersed and remain in the aqueous phase, thereby creating a competitive adsorption with that of MLDH, which led to the lesser efficiency of extraction. Since the SDS is an anionic surfactant and PAEs are anionic compounds, the interaction between SDS-MLDH and PAEs was through hydrophobic groups, with few if any electrostatic interactions. Thus, in the phases of semi-micelles, mixed-micelles and micelles, they could be absorbed with target chemicals. Therefore, a larger range of concentrations of SDS was added. Greater efficiency of extraction was observed when $10-50 \mathrm{mg}$ SDS/30 mg MLDH was used. Finally, $20 \mathrm{mg}$ SDS/30 mg MLDH was chosen for the subsequent experiments.

\subsection{Effect of adsorption equilibrium time on extraction}

Shorter absorption path is another advantage of nano SPE agent, which helps equilibrium achieved quickly. This characteristic was demonstrated by results of studies with the mesoporous magnetic LDH, extraction agent. To ensure sufficient contact between MLDH, SDS, and PAEs were evenly dispersed in aqueous solutions by use of ultrasonic treatment, which formed a homogeneous, turbid liquid. The extraction agent has a strong adsorption capacity for PAEs and a short diffusion path so the absorption equilibrium will be achieved quickly. This was demonstrated by the observation that the effect of equilibrium time to the efficiency of extraction was relatively small. Efficiency of extraction was more than $90 \%$ at equilibrium, which was reached within $5 \mathrm{~min}$. To insure efficient extraction with the minimum time, an optimum time for extraction of 10 min was selected for use in subsequent experiments.

\subsection{Effect of resolving condition on extraction}

PAEs adsorbed onto solid-phase nano extraction agent can be eluted by a small amount of organic solvent. Volumes and concentrations of acetonitrile and methanol as eluents were investigated. Acetonitrile had better elution capacity than did methanol. For instance, $12 \mathrm{~mL}$ of acetonitrile ( $4 \mathrm{~mL} \times 3$ times) can elute analytes off MLDH. Finally, $12 \mathrm{~mL}$ acetonitrile $(4 \mathrm{~mL} \times 3$ times, processed with ultrasound for $10 \mathrm{~s}$ during the elution) was selected for elution of target analytes.

\subsection{Effect of solution volume on extraction}

Breakthrough volume is a major parameter in SPE and preconcentration of samples. It significantly affects preconcentration factor, reproducibility and reliability of results. Efficiency of extraction was inversely proportional to volume of eluent in the range of 100-550 mL. Extraction recovery for DBP, DCP, and DOP from water being extracted with a set mass of MLDH $(30 \mathrm{mg})$, but always greater than $85 \%$, which demonstrated that the capacity for absorbance was dynamic and the conditions selected sufficient to allow for optimal recovery of analytes. A volume of $400 \mathrm{~mL}$ was chosen for use in subsequent studies. Target analytes adsorbed onto SDS-MLDH were then eluted by use of acetonitrile. By concentrating the eluents ( $12 \mathrm{~mL}$ of acetonitrile solution) to $0.5 \mathrm{~mL}$ with nitrogen flow, a preconcentration factor of 800 was achieved.

\subsection{Effect of ionic strength on extraction}

Ionic strength can change the chemical activity of charged ions and molecules in solution as well as that of the adsorbent, and then effects the adsorption efficiency. To investigate the effect of ionic strength on efficiency of adsorption a range of concentrations (0.0-0.2 M) of $\mathrm{NaCl}$ were studied (Fig. 5C). Increasing ionic strength improved the hydrophobic effect between the SDS hydrophobic grouping on the extraction agent and PAEs, which will improve adsorbance. Maximum efficiency was observed at approximately $0.05 \mathrm{M}$, while greater ionic strength increased viscosity of the solution and slowed migration of target analytes to the solid phase, which lead to lesser efficiency of adsorption. Thus, an ionic strength of $0.05 \mathrm{M}$ was selected for use in subsequently experiments.

\subsection{Effect of humic acid on efficiency of extraction}

Humic acids (HAs) and fulvic acids (FAs), are typical natural organic matters (NOM) that are common in environmental samples of water. Concentrations of HA/FA in environment samples are in the range $0.2-50 \mu \mathrm{g} \mathrm{mL}^{-1}$ [8]. FAs are generally smaller with nominal molecular mass of greater than 500 daltons while HAs are typically greater than $500 \mathrm{Da}$ in molecular mass. Many organic compounds can be adsorbed onto HAs due to the fact that the quinonyl, carboxyl, and phenolic hydroxyl groups on the polyphenolic structural framework that consists of both alkyl and aromatic groups. HAs can be adsorbed onto the surface of solid-phase adsorbants of extracting organics from water. They can thus block these sites of adsorption and interfere with extraction of target analytes. Efficiency of extraction was found to be inversely proportional to the concentration of HA/FA which suggest that there is competitive adsorption between the HA/FA and target, organic analytes for sites on the MLDH sorbent (Fig. 5D). This can be explained by the fact that, under acidic conditions ( $\mathrm{pH} 4.5$ ), HA/FA carry net negative charges and MLDH carries a net positive charge. Thus, HA/FA will be adsorbed by electrostatic attraction onto the extraction agent and therefore occupy potential sites of adsorption to SDS. This results in target analytes, such as PAEs to combine with free SDS in water, and results in lesser recoveries. Also, it is possible that, due to the strong adsorbent capacity of HA/FA, PAEs directly react with free $\mathrm{HA} / \mathrm{FA}$ in water which results in poorer efficiencies of extraction. We expect that the extraction of PAEs onto MLDH would not be affected in water samples in which concentration of natural organic matter is less. Magnetic extraction sorbent with strong anti-interference capacity will be developed in our further study. 
Table 1

PAEs detecting concentration and standard recovering concentration in several environment water samples.

\begin{tabular}{|c|c|c|c|c|c|c|}
\hline \multirow[t]{2}{*}{ Water sample } & \multirow[t]{2}{*}{ Analytes } & \multicolumn{3}{|c|}{ Detected $^{\mathrm{a}}\left(\mathrm{ng} \mathrm{mL}^{-1}\right)$} & \multicolumn{2}{|l|}{ Recovery $^{\mathrm{b}}(\%) \pm \mathrm{RSD}$} \\
\hline & & Blank & $0.5 \mathrm{ng} \mathrm{mL}^{-1}$ spiked & $5 \mathrm{ng} \mathrm{mL}^{-1}$ spiked & $0.5 \mathrm{ng} \mathrm{mL}^{-1}$ spiked & $5 \mathrm{ng} \mathrm{mL}^{-1}$ spiked \\
\hline \multirow[t]{4}{*}{ Tap water } & DPP & $\mathrm{ND}^{\mathrm{c}}$ & 0.466 & 5.01 & $93 \pm 6$ & $100 \pm 3$ \\
\hline & DBP & ND & 0.478 & 4.65 & $96 \pm 2$ & $93 \pm 4$ \\
\hline & DCP & ND & 0.512 & 4.73 & $102 \pm 4$ & $95 \pm 5$ \\
\hline & DOP & ND & 0.501 & 3.19 & $100 \pm 3$ & $64 \pm 6$ \\
\hline \multirow[t]{4}{*}{ Beiyun river } & DPP & 0.07 & 0.493 & 4.41 & $99 \pm 2$ & $88 \pm 1$ \\
\hline & DBP & $<\mathrm{LOQ}$ & 0.490 & 5.08 & $98 \pm 1$ & $101 \pm 3$ \\
\hline & DCP & ND & 0.428 & 5.06 & $86 \pm 4$ & $101 \pm 2$ \\
\hline & DOP & ND & 0.504 & 4.11 & $101 \pm 5$ & $82 \pm 5$ \\
\hline \multirow[t]{4}{*}{ Juma river } & DPP & $<\mathrm{LOQ}$ & 0.428 & 3.47 & $86 \pm 6$ & $69 \pm 4$ \\
\hline & DBP & $<\mathrm{LOQ}$ & 0.507 & 3.94 & $101 \pm 3$ & $79 \pm 5$ \\
\hline & DCP & ND & 0.461 & 5.09 & $92 \pm 4$ & $102 \pm 3$ \\
\hline & DOP & ND & 0.501 & 3.14 & $100 \pm 5$ & $63 \pm 6$ \\
\hline
\end{tabular}

a Three parallel determination results.
b RSD of three determinations.

c Not detected.

Table 2

Linearity range, calibration equations, correlation coefficient and limit of detection of the working curve.

\begin{tabular}{|c|c|c|c|c|c|}
\hline Analytes & Linearity range $\left(\mathrm{ng} \mathrm{mL}^{-1}\right)$ & Calibration equations & Correlation coefficient $\left(r^{2}\right)$ & RSD (\%) & $\operatorname{LOD}\left(\mathrm{ng} \mathrm{L}^{-1}, \mathrm{~S} / \mathrm{N}=3\right)$ \\
\hline DPP & $0.1-10$ & $y=2.01 x-0.464$ & 0.9897 & 6.867 & 12.3 \\
\hline DBP & $0.1-10$ & $y=1.286 x-0.3123$ & 0.9864 & 6.976 & 18.7 \\
\hline DCP & $0.1-10$ & $y=1.0856 x-0.2398$ & 0.9852 & 3.379 & 36.5 \\
\hline DOP & $0.1-10$ & $y=0.5614 x+0.0988$ & 0.9925 & 2.175 & 15.6 \\
\hline
\end{tabular}

Table 3

Comparison of the present method with other sorbent-based methods for the determination of PAEs.

\begin{tabular}{|c|c|c|c|c|c|c|c|c|}
\hline Method & Extraction technique $^{\mathrm{a}}$ & Sorbent/cartridge & $\operatorname{LOD}\left(\mathrm{ng} \mathrm{L}^{-1}\right)$ & RSD (\%) & $\begin{array}{l}\text { Sample } \\
\text { volume }(\mathrm{mL})\end{array}$ & $\begin{array}{l}\text { Sorbent } \\
\text { amount (mg) }\end{array}$ & $\begin{array}{l}\text { Extraction } \\
\text { time (min) }\end{array}$ & Ref. \\
\hline HPLC-UV & AHMSPE & $\mathrm{Fe}_{3} \mathrm{O}_{4} /$ meso-SiO 2 & $12-32$ & $2.3-5.4$ & 250 & 100 & 20 & [36] \\
\hline HPLC-UV & MSPE & $\mathrm{ALG} @ \mathrm{C}_{18}-\mathrm{Fe}_{3} \mathrm{O}_{4}-\mathrm{TN}$ & $11-36$ & $0.3-11$ & 500 & 70 & 50 & [20] \\
\hline HPLC-UV & MSPE & $\mathrm{Fe}_{3} \mathrm{O}_{4} @ \mathrm{C}_{18} @ \mathrm{Ba}^{2+}-\mathrm{ALG}$ & - & 1-9 & 500 & 100 & 35 & [37] \\
\hline HPLC-UV & EPS & CTAB-TN & - & $0.4-7$ & 250 & 100 & $>60$ & [2] \\
\hline GC-MS & DI-SPME & MWCNTs-PPy & $50-100$ & $9.3-12.1$ & 10 & - & 25 & [38] \\
\hline GC-MS & MSPE & $\mathrm{Fe}_{3} \mathrm{O}_{4} @ P P y$ & 6-68 & $3.4-11.7$ & 20 & 30 & 15 & [39] \\
\hline HPLC-UV & MSPE & $\mathrm{Fe}_{3} \mathrm{O}_{4} @ \mathrm{SiO}_{2}-\mathrm{G}$ & $70-100$ & $2.7-6.1$ & 100 & 15 & 10 & [6] \\
\hline HPLC-UV & AHMSPE & MLDH-SDS & $12-36$ & $1-7$ & 400 & 30 & 10 & This work \\
\hline
\end{tabular}

a AHMSPE, admicelles/hemimicelles magnetic solid-phase extraction; MSPE, magnetic solid-phase extraction; EPS, extraction by packed sorbent in cartridge column; DI-SPME, direct immersion solid-phase microextraction.

\subsection{Relevant parameters of MSPE-HPLC analysis methods for}

PAES

By using the optimized solid-phase extraction methods (Table 1), based on magnetic solid-phase extractionchromatography, PAEs were extracted from water. The linear working range of the standard curve is $0.1-10 \mathrm{ng} \mathrm{mL}^{-1}$, with a coefficient of determination $\left(r^{2}\right)$ of $>0.985$. The limit of detection (LODs) for analytes, defined as 3 times of $S N R(S / N=3)$ for DPP, DBP, DCP, and DOP were $12.3,18.7,36.5$, and $15.6 \mathrm{ng} \mathrm{L}^{-1}$, respectively. The relative standard deviation (RSD) of the method was $2-7 \%$.

\subsection{Methods validation with field samples}

To examine the utility of the method, concentrations of DPP, DBP, DCP, and DOP of several environment water samples were determined by use of the optimized method (Table 2). Concentrations of PAEs in the Beiyun and Juma River were low and none of the PAEs were detected in samples of Beijing tap water. The recovery

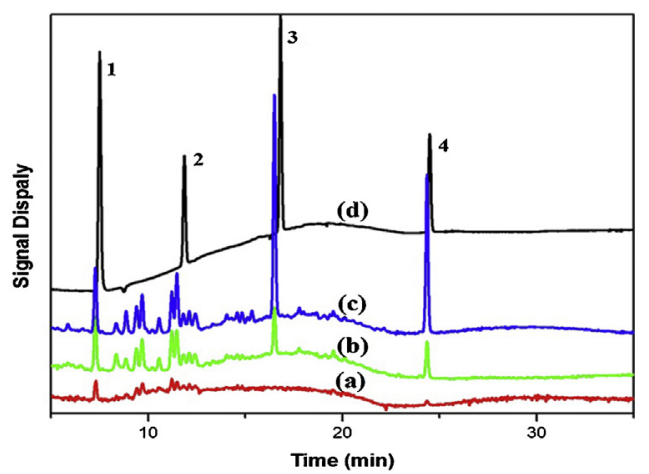

Fig. 6. MSPE-HPLC-UV chromatogram of PAEs in the Juma River water sample and its standard sample. (a) Juma River water sample; (b) add $0.50 \mathrm{ng} \mathrm{mL}^{-1}$ of analyte in the Juma River sample; (c) add $5.0 \mathrm{ng} \mathrm{mL}^{-1}$ of analyte in the Juma River sample and (d) blank sample. 1, DPP; 2, DBP; 3, DCP; 4, DOP. 
of DPP, DBP, DCP, and DOP from three water samples are $69-101 \%$, $79-101 \%, 86-102 \%$, and $63-100 \%$, respectively, with RSD of $1-6 \%$ (Fig. 6).

To compare the present method with other sorbent-based extraction techniques used for the determination of PAEs, analytical performance data of the methods have been summarized in Table 3. The LOD of the proposed method was lower than most of those obtained by other HPLC-based techniques. Compared to cartridge, the procedure for preconcentration was simplified and time to complete the extraction was lesser. To pretreat $400 \mathrm{~mL}$ of water samples, by use of MLDH adsorbents required only $10 \mathrm{~min}$. The enrichment factor has up to 800 with $30 \mathrm{mg}$ of MLDH.

\section{Conclusion}

The method combines the advantages of nanometer/mesoporous materials, self-assembly modification, and magnetic separation technology. Compared with solid-phase extraction that is based on modification of surface active agents, the advantages of this method are: (i) Rapid synthesis of MLDH and milder conditions for formation, high throughput, low cost; (ii) The mesoporous materials have a large specific surface area and adsorption capacity is high; the amount of extraction agent required is small (need only $30 \mathrm{mg}$ MLDH and $20 \mathrm{mg}$ SDS); (iii) Magnetic separation can be achieved in a short time; and the speed with which large volumes of water from the environment is greatly improved. The analytical method developed based on these adsorbents is stable, reproducible, and can be used to simultaneously process multiple samples. The mesoporous diameter can be controlled by methods used in its preparation to give the material some size exclusion which allows the micromolecule pollutant to enter and keeps the macromolecule such as protein, nucleic acid, and HA out. For complex samples of water from the environment, the method can be adapted for use with a range or organic pollutants.

\section{Acknowledgement}

This work was jointly supported by National Natural Science Foundation of China (41222026, 41130743, 21277152).

\section{References}

[1] H.Y. Niu, Y.O Cai, Y.L. Shi, F.S. Wei, J.M. Liu, G.B. Jiang A new solid-phase extraction disk based on a sheet of single-walled carbon nanotubes, Anal. Bioanal. Chem. 392 (2008) 927-935.

[2] H.Y. Niu, Y.Q. Cai, Y.L. Shi, F.S. Wei, S.F. Mou, G.B. Jiang, Cetyltrimethylammonium bromide-coated titanate nanotubes for solid-phase extraction of phthalate esters from natural waters prior to high-performance liquid chromatography analysis, J. Chromatogr. A 1172 (2007) 113-120.

[3] J.D. Li, Y.Q. Cai, Y.L. Shi, S.F. Mou, G.B. Jiang, Analysis of phthalates via HPLC-UV in environmental water samples after concentration by solid-phase extraction using ionic liquid mixed hemimicelles, Talanta 74 (2008) 498-504.

[4] T. Zeng, X.L. Zhang, Y.R. Ma, S.H. Wang, H.Y. Niu, Y.Q. Cai, A functional rattletype microsphere with a magnetic-carbon double-layered shell for enhanced extraction of organic targets, Chem. Commun. 49 (2013) 6039-6041.

[5] A.A. Asgharinezhad, N. Mollazadeh, H. Ebrahimzadeh, F. Mirbabaei, N. Shekari, Magnetic nanoparticles based dispersive micro-solid-phase extraction as novel technique for coextraction of acidic and basic drugs from biological fluids and waste water, J. Chromatogr. A 1338 (2014) 1-8.

[6] W.N. Wang, R.Y. Ma, Q.H. Wu, C. Wang, Z. Wang, Fabrication of magnetic microsphere-confined graphene for the preconcentration of some phthalate esters from environmental water and soybean milk samples followed by their determination by HPLC, Talanta 109 (2013) 133-140

[7] Y. Zou, Y.Z. Chen, Z.H. Yan, C.Y. Chen, J.P. Wang, S.Z. Yao, Magnetic solid phase extraction based on tetrabenzyl modified $\mathrm{Fe}_{3} \mathrm{O}_{4}$ nanoparticles for the analysis of trace polycyclic aromatic hydrocarbons in environmental water samples, Analyst 138 (2013) 5904-5912.

[8] X.L. Zhang. H.Y. Niu, W.H. Li, Y.L. Shi, Y.O Cai, A core-shell magnetic mesoporous silica sorbent for organic targets with high extraction performance and antiinterference ability, Chem. Commun. 47 (2011) 4454-4456.
[9] L. Li, Y.J. Feng, Y.S. Li, W.R. Zhao, J.L. Shi, $\mathrm{Fe}_{3} \mathrm{O}_{4}$ core/layered double hydroxide shell nanocomposite: versatile magnetic matrix for anionic functional materials, Angew. Chem. Int. Edit. 48 (2009) 5888-5892.

[10] F. Mi, X.T. Chen, YW. Ma, S.T, Yin, F. Yuan, H. Zhang Facile synthesis of hierarchical core-shell $\mathrm{Fe}_{3} \mathrm{O}_{4} @ \mathrm{MgAl}-\mathrm{LDH} @ \mathrm{Au}$ as magnetically recyclable catalysts for catalytic oxidation of alcohols, Chem. Commun. 47 (2011) 12804-12806.

[11] D.K. Pan, H. Zhang, T. Fan, J.G. Chen, X. Duan, Nearly monodispersed core-shel structural $\mathrm{Fe}_{3} \mathrm{O}_{4} @$ DFUR-LDH submicro particles for magnetically controlled drug delivery and release, Chem. Commun. 47 (2011) 908-910.

[12] H. Zhang, G.Y. Zhang, X. Bi, X.T. Chen, Facile assembly of a hierarchical core@shell $\mathrm{Fe}_{3} \mathrm{O}_{4} @ \mathrm{CuMgAl}-\mathrm{LDH}$ (layered double hydroxide) magnetic nanocatalyst for the hydroxylation of phenol, J. Mater. Chem. A 1 (2013) 5934-5942.

[13] Y.F. Zhao, S. He, M. Wei, D.G. Evans, X. Duan, Hierarchical films of layered double hydroxides by using a sol-gel process and their high adaptability in water treatment, Chem. Commun. 46 (2010) 3031-3033.

[14] A. Wongariyakawee, F. Schäeffel, J.H. Warner, D. O'Hare, Surfactant directed synthesis of calcium aluminum layered double hydroxides nanoplatelets, J. Mater. Chem. 22 (2012) 7751-7756

[15] H. Zhang D.K. Pan, K. Zou, J. He, X. Duan, A novel core-shell structured magnetic organic-inorganic nanohybrid involving drug-intercalated layered double hydroxides coated on a magnesium ferrite core for magnetically controlled drug release, J. Mater. Chem. 19 (2009) 3069-3077.

[16] S. Tang G.H. Chia, Y.P. Chang H. Lee, Automated dispersive solid-phase extraction using dissolvable $\mathrm{Fe}_{3} \mathrm{O}_{4}$-layered double hydroxide core-shell microspheres as sorbent, Anal. Chem. 86 (2014) 11070-11076.

[17] M. Saraji, M. Ghani, Dissolvable layered double hydroxide coated magnetic nanoparticles for extraction followed by high performance liquid chromatography for the determination of phenolic acids in fruit juices, J. Chromatogr. A 1366 (2014) 24-30.

[18] M.F. Shao, F.Y Ning J.W. Zhao, M. Wei, D.G. Evans, X. Duan, Preparation of $\mathrm{Fe}_{3} \mathrm{O}_{4} @ \mathrm{SiO}_{2} @$ layered double hydroxide core-shell microspheres for magnetic separation of proteins, J. Am. Chem. Soc. 134 (2012) 1071-1077.

[19] M.F. Shao, F.Y. Ning, Y.F.Zhao, J.W.Zhao, M. Wei, D.G. Evans, X. Duan, Core-shell layered double hydroxide microspheres with tunable interior architecture for supercapacitors, Chem. Mater. 24 (2012) 1192-1197.

[20] H.Y. Niu, S.X. Zhang, X.L. Zhang, Y.Q. Cai, Alginate-polymer-caged, C18 functionalized magnetic titanate nanotubes for fast and efficient extraction of phthalate esters from water samples with complex matrix, ACS Appl. Mater. Inter. 2 (2010) 1157-1163.

[21] X. Zhang, H. Niu, Y. Pan, Y. Shi, Y. Cai, Chitosan-coated octadecyl-functionalized magnetite nanoparticles: preparation and application in extraction of trace pollutants from environmental water samples, Anal. Chem. 82 (2010) 2363-2371.

[22] X. Zhao, Y. Shi, Y. Cai, S. Mou, Cetyltrimethylammonium bromide-coated magnetic nanoparticles for the preconcentration of phenolic compounds from environmental water samples, Environ. Sci. Technol. 42 (2008) 1201-1206.

[23] L. Sun, C.Z. Zhang, L.G. Chen, J. Liu, H.Y. Jin, H.Y. Xu, L. Ding, Preparation of alumina-coated magnetite nanoparticle for extraction of trimethoprim from environmental water samples based on mixed hemimicelles solid-phase extraction, Anal. Chim. Acta 638 (2009) 162-168.

[24] J.D. Li, X.L. Zhao, Y.L. Shi, Y.Q. Cai, S.F. Mou, G.B. Jiang Mixed hemimicelles solidphase extraction based on cetyltrimethylammonium bromide-coated nanomagnets $\mathrm{Fe}_{3} \mathrm{O}_{4}$ for the determination of chlorophenols in environmental water samples coupled with liquid chromatography/spectrophotometry detection, J. Chromatogr. A 1180 (2008) 24-31.

[25] H. He, D.H. Yuan, Z.Q. Gao, D.L. Xiao, H. He, H. Dai, J. Peng, N. Li, Mixed hemimicelles solid-phase extraction based on ionic liquid-coated $\mathrm{Fe}_{3} \mathrm{O}_{4} / \mathrm{SiO}_{2}$ nanoparticles for the determination of flavonoids in bio-matrix samples coupled with high performance liquid chromatography, J. Chromatogr. A 1324 (2014) 78-85.

[26] O. Liu, J.B. Shi, T. Wang, F. Guo, L.H. Liu, G.B. Jiang, Hemimicelles/admicelles supported on magnetic graphene sheets for enhanced magnetic solid-phase extraction, J. Chromatogr. A 1257 (2012) 1-8

[27] Y.H. Deng, D.W. Qi, C.H. Deng, X.M. Zhang, D.Y. Zhao, Superparamagnetic highmagnetization microspheres with an $\mathrm{Fe}_{3} \mathrm{O}_{4} @ \mathrm{SiO}_{2}$ core and perpendicularly aligned mesoporous $\mathrm{SiO}_{2}$ shell for removal of microcystins, J. Am. Chem. Soc. 130 (2008) 28-29.

[28] X.L. Zhao, Y.L. Shi, T. Wang Y.O Cai, G.B. Jiang, Preparation of silica-magnetite nanoparticle mixed hemimicelle sorbents for extraction of several typical phenolic compounds from environmental water samples, J. Chromatogr. A 1188 (2008) 140-147.

[29] S.X. Zhang, H.Y. Niu, Y.Y. Zhang, J.S. Liu, Y.L. Shi, X.L. Zhang Y.Q Cai, Biocompatible phosphatidylcholine bilayer coated on magnetic nanoparticles and their application in the extraction of several polycyclic aromatic hydrocarbons from environmental water and milk samples, J. Chromatogr. A 1238 (2012) 38-45.

[30] Y.F. Zhu, E. Kockrick, T. Ikoma, N. Hanagata, S. Kaskel, An efficient route to rattletype $\mathrm{Fe}_{3} \mathrm{O}_{4} @ \mathrm{SiO}_{2}$ hollow mesoporous spheres using colloidal carbon spheres templates, Chem. Mater. 21 (2009) 2547-2553.

[31] L.Z. Tong, J.H. Shi, X.Z. Ren, O.H. Li, H. Ding, H. Yang, Multifunctional nanocomposites with different coupling agents: synthesis, luminescent and magnetic properties, J. Nanopart. Res. 15 (2013) 1-9.

[32] W. Li, B.L. Zhang, X.J. Li, H.P. Zhang, Q.Y.Zhang, Preparation and characterization of novel immobilized $\mathrm{Fe}_{3} \mathrm{O}_{4} @ \mathrm{SiO}_{2} @ \mathrm{mSiO}_{2}-\mathrm{Pd}(0)$ catalyst with large pore-size mesoporous for Suzuki coupling reaction, Appl. Catal. A: Gen. 459 (2013) 65-72. 
[33] S.H. Han, S.P. Xu, W.G. Hou, D.J. Sun, C.G. Zhang, G.T. Wang, Study on electric property at interface of positive sol of magnesium aluminum hydroxide, Chin. J. Chem. 15 (1997) 304-312.

[34] S. Tang, H.K. Lee, Application of dissolvable layered double hydroxides as sorbent in dispersive solid-phase extraction and extraction by co-precipitation for the determination of aromatic acid anions, Anal. Chem. 85 (2013) $7426-7433$.

[35] C.C. Hsu, C.W. Whang, Microscale solid phase extraction of glyphosate and aminomethylphosphonic acid in water and guava fruit extract using alumina-coated iron oxide nanoparticles followed by capillary electrophoresis and electrochemiluminescence detection, J. Chromatogr. A 1216 (2009) $8575-8580$.

[36] P.L. Liu, Y.P. Xu, P. Zheng, H.W. Tong, Y.X. Liu, Z.G. Zha, Q.D. Su, S.M. Liu, Mesoporous silica-coated magnetic nanoparticles for mixed hemimicelles solid-phase extraction of phthalate esters in environmental water samples with liquid chromatographic analysis, J. Chin. Chem. Soc. 60 (2013) 53-62.

[37] S.X. Zhang, H.Y. Niu, Y.Q. Cai, Y.L. Shi, Barium alginate caged $\mathrm{Fe}_{3} \mathrm{O}_{4} @ \mathrm{C} 18$ magnetic nanoparticles for the pre-concentration of polycyclic aromatic hydrocarbons and phthalate esters from environmental water samples, Anal. Chim. Acta 665 (2010) 167-175.

[38] H. Asadollahzadeh, E. Noroozian, S. Maghsoudi, Solid-phase microextraction of phthalate esters from aqueous media by electrochemically deposited carbon nanotube/polypyrrole composite on a stainless steel fiber, Anal. Chim. Acta 669 (2010) 32-38

[39] J.R. Meng, J. Bu, C.H. Deng, X.M. Zhang, Preparation of polypyrrole-coated magnetic particles for micro solid-phase extraction of phthalates in water by gas chromatography-mass spectrometry analysis, J. Chromatogr. A 1218 (2011) 1585-1591. 